\title{
Design and Development of a Soft-Sensor for Ammonia Degradation and Nitrite Accumulation in an Activated Sludge reactor
}

\author{
Carlos Muñoz P. ${ }^{1}$, Daniel Rojas A. ${ }^{1}$, Christian Antileo H. ${ }^{2}$, \\ ${ }^{1}$ Dept. of Electrical Engineering, Universidad de la Frontera, \\ ${ }^{2}$ Dept. of Chemical Engineering, Universidad de la Frontera, \\ Av. Francisco Salazar 01145 Temuco, Chile, \\ email : comunoz@ufro.cl
}

\begin{abstract}
A soft-sensor for on-line estimation of ammonia degradation $(\alpha)$ and nitrite accumulation $(\beta)$ is proposed in this paper. The soft-sensor has showed a good behavior in the following of trends and has got final values very close to the experimental analysis. Thought this soft-sensor was not conceived for replacing the laboratory analysis, gives $\alpha$ and $\beta$ estimations for all the instants in between the laboratory sample taking. The data resulting from the laboratory analysis is used to update the model parameters on which the soft-sensor is based on. Furthermore, the model is used to feed an on-line optimization system to look for the $\mathrm{pH}$ and $\mathrm{O}_{2}$ set-points whose gives maximum ammonia degradation $(\alpha)$ and nitrite accumulation $(\beta)$. This optimization system is executed every time that the model parameters are updated.
\end{abstract}

Keywords: soft-sensor, on-line optimization, fuzzy systems.

\section{INTRODUCTION}

The biological process of nitrificaction - denitrificaction, allows removal economic of high nitrogen loads in wastewater treatment plant (WWTP). In this process, the ammonia contained in the industrial wastewater is reduced to nitrite by the autotrophic microorganism denominated Nitrosomonas. Normally, a fraction of the nitrite is transformed to nitrate by action of a second group of autotrophic microorganism called Nitrobacter. In the denitrification stage the nitrite is reduced to nitrogen gas by action of the heterotrophic denitrifying bacteria. In this stage the nitrate generated previously must be reconverted to nitrite, meaning this unnecessary energy cost.

Antileo et al [2], reported that using a very precise environmental conditions, in particular, maintaining low concentrations for $\mathrm{O}_{2}$ and high values for $\mathrm{pH}$, results in the inhibition of the Nitrobacter action and in the enhancement of the ammonia degradation. However, the environmental conditions that favor the inhibition of the Nitrobacter may change in time [7]. This suggests the necessity to develop a supervisory control system to assist in the task of finding the optimal values for $\mathrm{pH}$ and $\mathrm{O}_{2}$ setpoints. The main assumption is that using this supervisory control system, it is possible to maintain in the long term, favorable environmental conditions for the growth of Nitrosomonas and unfavorable conditions for the growth of the Nitrobacter. Thus, high efficiency will stay in the time, meaning this, high ammonium degradation along with low nitrate accumulation. In this paper, the goal is the development of a supervisory control system to maintain in the long term high efficiency in an activated sludge reactor, applying changes only on the $\mathrm{pH}$ and $\mathrm{O}_{2}$ set-points.

The $\mathrm{pH}$ and $\mathrm{O}_{2}$ regulatory control for the activated sludge reactor was approached in Huenupán [4], where PID linear controllers were used and tuned by making benchmarking with predictive controllers. The operation achieved by the PID controllers was outstanding, eliminating totally the interactions produced by the biomass activity in the operation zone specified by Antileo et al [2] (7,5 to 8,5 for $\mathrm{pH}$ and 0,2 to $4,5 \mathrm{mg} / \mathrm{L}$ for $\left.\mathrm{O}_{2}\right)$. Simultaneously, Araneda [3] implemented a simulator for the nitrification process, in which was established that although the regulation in this range of $\mathrm{pH}$ and $\mathrm{O}_{2}$ may be approached with excellent results using linear control techniques, the complexity of the behavior in the nitrite accumulation $(\alpha)$ and in the ammonia degradation $(\beta)$ suggest the use of design tools for nonlinear systems.

The problem is increased due the lack of on-line measurements for ammonia, nitrite and nitrate. These real time measurements are feasible only for large scale processes because they use very expensive on-line analyzers that require continuous samples. In order to face the implementation problem of a similar supervisory control system, Tomiello et al [1] use in a daily basis experimental analysis for $\mathrm{COD}, \mathrm{NH}_{3}$ - and $\mathrm{NO}_{2}$. The experimental analysis allows developing a hierarchical fuzzy controller based on a supervisory and regulatory control stages for the biological nitrification - denitrification process. By using empirical knowledge the supervisory control makes a global diagnostic of the process, and makes choices about the set-points changes. In resume, Tomiello didn't look for optimal operation neither used on line data for this purpose.

This work proposes a soft-sensor for on-line estimation of ammonia degradation and nitrite accumulation. The soft-sensor is based on first order linear multi-models, mixed by using fuzzy logic tools. The multi-model of the soft-sensor is also used by the optimization system, since it gives results for each $\mathrm{pH}$ and $\mathrm{O}_{2}$ combination feasible as input to the reactor. For this an objective function, that 
represents the reactor efficiency, is used as output. This objective function is maximized with respect to the $\mathrm{pH}$ and $\mathrm{O}_{2}$ set-points, constrained to the interval in the optimization variables. The on-line optimization is included in the control strategy as a supervisory control module that feed the set-points on the regulatory control module.

\section{Process Description}

\section{A. The Nitrification Process in an Activated Sludge System}

The figure 1 shows the flow sheet of a nitrifying activated sludge reactor composed by Continuous Stirred Tank Reactor (CSTR) and a settler. In this reactor an inlet to the tank with a considerable ammonia concentration is oxidized to nitrite due to the action of the autotrophic microorganisms called Nitrosomonas. The efficiency of the ammonia oxidation is quantified by means of $\alpha$, given by Ec. (1). In addition, for nitrite accumulation in the reactor, which is produced by Nitrosomonas and oxidized to nitrate by Nitrobacter, an additional index $\beta$ is defined in Equation 2.

$$
\alpha=\frac{\mathrm{c}_{\mathrm{O}(\mathrm{N}-3)}-\mathrm{c}_{\mathrm{R}(\mathrm{N}-3)}}{\mathrm{c}_{\mathrm{O}(\mathrm{N}-3)}}
$$

(Ammonia degradation rate)

$$
\beta=\frac{\mathrm{c}_{\mathrm{R}(\mathrm{N}+3)}}{\mathrm{c}_{\mathrm{R}(\mathrm{N}+3)}+\mathrm{c}_{\mathrm{R}(\mathrm{N}+5)}}
$$

(Nitrite accumulation rate)

With: $0 \leq \alpha \leq 1$ y $0 \leq \beta \leq 1$

The final requirement for this process is to maintain in stable form and during all the reactor operation, both values, $\alpha$ and $\beta$, very near to $100 \%$, which makes possible to minimize simultaneously the ammonia and the nitrate production in the effluent [5][6].

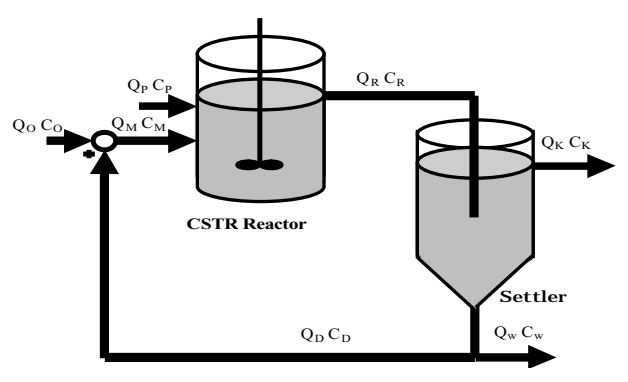

Figure 1. Flow sheet of an activated sludge reactor with recirculation.

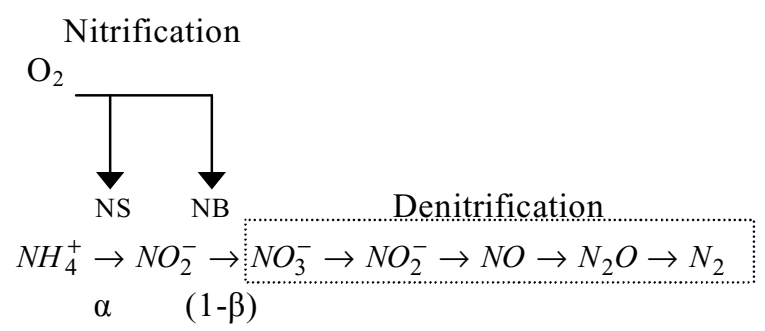

Figure 2. Flow sheet of nitrificaction - denitrificaction process.

\section{B. Instrumentation and Process Control}

The flow sheet of the pilot plant and his instrumentation is given in figure 3 . The pilot plant consists of an activated sludge reactor, instrumented with sensors and transmitters and a PLC that allows to measure every 1 second, the signals of $\mathrm{pH}$ and $\mathrm{O}_{2}$, and to execute routines of regulatory control that automatically manipulates membrane pumps to regulate the sodium carbonate addition, and ON/OFF valves to regulate the air injection to the reactor by using pulse wide modulation. Also there are laboratory analyses that give values of nitrite, nitrate and ammonia in the reactor in a daily basis (but with some omission, especially on the weekends). This plant operates with a constant ammonium feeding of $250 \mathrm{mg} / \mathrm{L} \mathrm{N}_{-} \mathrm{NH}_{4}{ }^{+}$, a temperature of $23{ }^{\circ} \mathrm{C}$, an restricted operation range $\left(0.8 \mathrm{mg} / \mathrm{L}<\mathrm{O}_{2}<1.0\right.$ $\mathrm{mg} / \mathrm{L}, 7.5<\mathrm{pH}<8.5$ ), recirculation rate of $60 \%$, biomass of $1000 \mathrm{mg} / \mathrm{L} \mathrm{SSV}$ and an hydraulic residence time (TRH) of 6 hours.

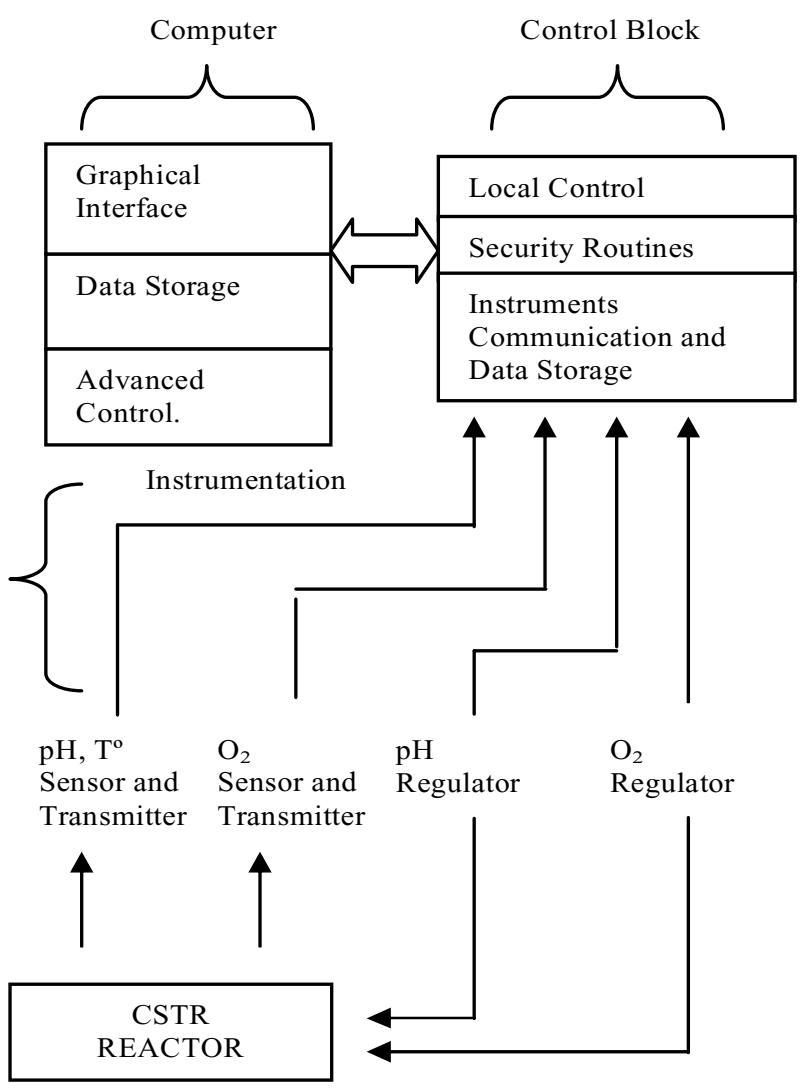

Figure 3. Flow sheet of the pilot plant and his instrumentation.

For the $\mathrm{pH}$ and $\mathrm{O}_{2}$ regulatory control PID linear controllers, with inferior response times to the 10 minutes, were considered. For monitoring tasks, a graphical interface was designed, which was developed using the Guide Matlab toolbox. This interface allows, every 1 second, obtain registries of the evolution of $\mathrm{pH}, \mathrm{O}_{2}$, opening of the air valve and addition of carbonate, in addition to modify in real time the reference and tuning parameters for the $\mathrm{pH}$ and $\mathrm{O}_{2}$ PID controllers. 


\section{The SofT-SEnSOR}

\section{A. Experimental Information Processing}

The $\alpha$ and $\beta$ soft-sensor uses a multi-model to estimate in real time the nitrite accumulation and ammonia degradation.

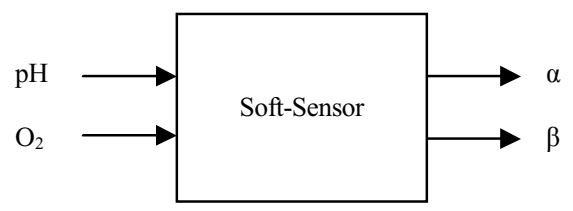

Figure 4. Representative block of the soft sensor

The information used to build the multi-model consists of records of data gathered during a time period of 8 months. The data records are composed of $\mathrm{pH}$ and $\mathrm{O}_{2}$ values acquired directly from the PLC and nitrite, nitrate and ammonia values obtained from laboratory analysis. Figure 5 shows, in a 60 days time interval, $\alpha$ and $\beta$ for different values of $\mathrm{pH}$ and $\mathrm{O}_{2}$.

In the figure 5 , it is observed that $\alpha$ and $\beta$ presents a heavy noise during the 60 days of the displayed registry. The noise is explained by the uncertainly of the laboratory measurement process, and it is one of the main difficulties in the proper identification of a representative model of the process, taking $\mathrm{pH}$ and $\mathrm{O}_{2}$ as inputs.

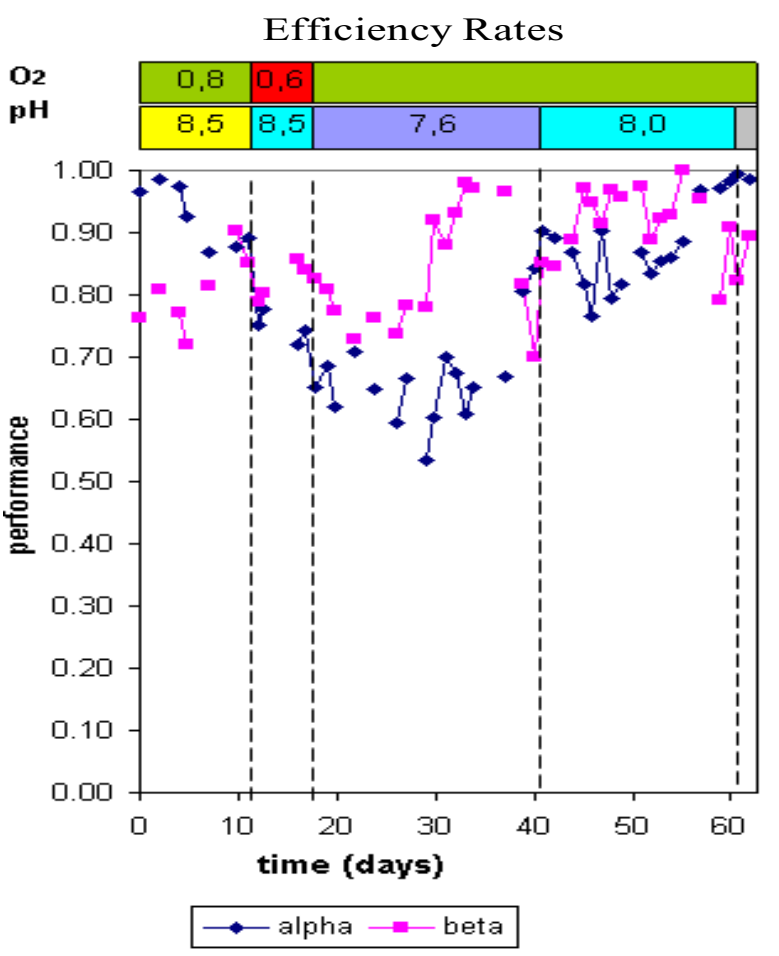

Figura 5. Experimental data.

In figure 5 it can be seen that there are patterns in $\alpha$ behavior that can not be associated to a movement of $\mathrm{pH}$ or $\mathrm{O}_{2}$. This behavior could be associated only to a very strong disturbances, such as the biomass concentration for example, which they affect the process dynamics. The amount of the disturbances suggests that a data preprocessing is necessary to identify suitable models for $\alpha$ and $\beta$. In this case the $\alpha$ and $\beta$ curves were smoothed to follow a trend in the cause-effect principle. Therefore, those data that can not be explained with this principle were eliminated.

The filtering process gives an approximate behavior of $\alpha$ and $\beta$ for specific operation zones, as it is shown in figure 7. The data corresponding to the time period between days 40 and 95 has a behavior that resembles a first order linear system response to a step input. This must be because while $\mathrm{O}_{2}$ is hold on, the correlation between $\alpha$ and $\beta$ with respect to the $\mathrm{pH}$ level is very high, allowing the use of linear systems identification techniques to model $\alpha$ and $\beta$ behavior using only the $\mathrm{pH}$ level as input.
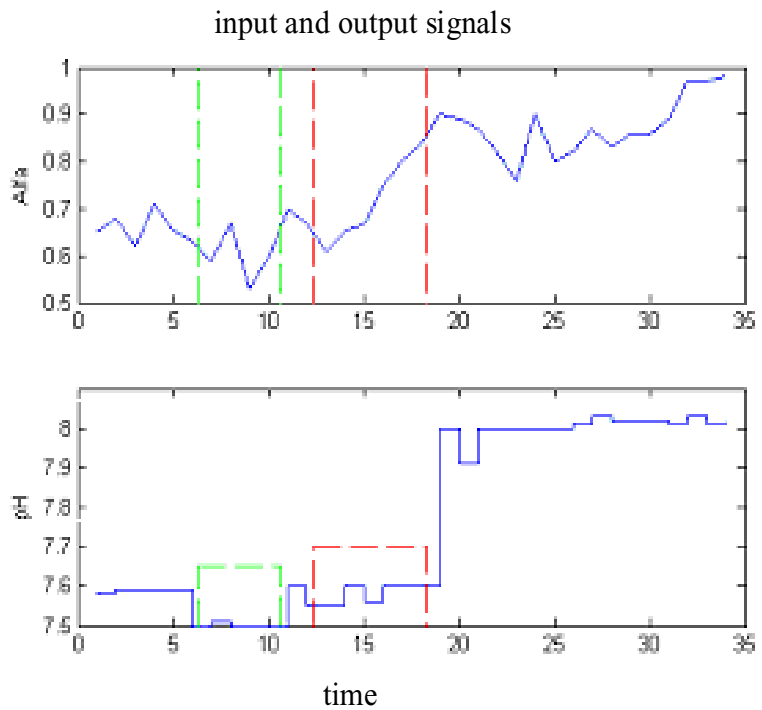

Figure 6. Without processing data

Unlike the $\mathrm{pH}$ level, the $\mathrm{O}_{2}$ presents a highly nonlinear relation with respect to $\alpha$ and $\beta$. In order to solve this problem, the fuzzy logic techniques allows using different single input - single output (SISO) linear models ( $\mathrm{pH}-\alpha$, $\mathrm{pH}-\beta$ ) depending on the $\mathrm{O}_{2}$ level in which one was operating the reactor. In this way, the resulting multimodel is capable to represent the highly nonlinear behavior of the process.

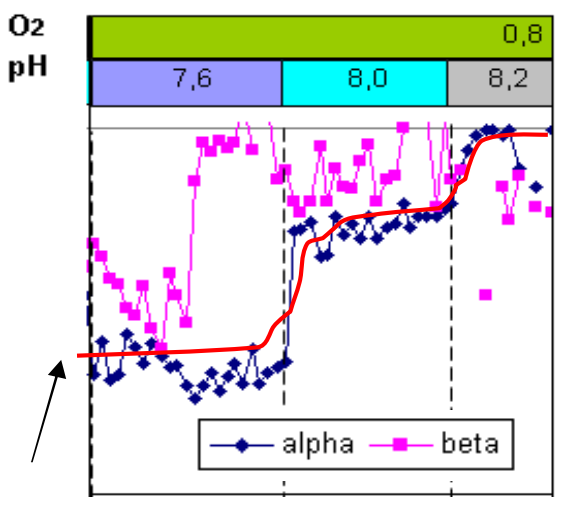

Figure 7. $\alpha$ first order system approximation 


\section{B. Models Identification}

Four first order models were identified: two for $\alpha$ and two for $\beta$, each one is valid only within an active interval, as it is shown in table 1, where the time basis is equal to one day.

\begin{tabular}{|l|l|}
\hline First Order Models & Active Interval \\
\hline$\alpha_{1}(t)=\theta_{11}^{\alpha} p H(t-1)+\theta_{12}^{\alpha} \alpha(t-1)$ & $\mathrm{O}_{2}=0.8 \mathrm{mg} / \mathrm{L}$ \\
with $\theta_{11}^{\alpha}=0.06$ and $\theta_{12}^{\alpha}=0.32$ & $7.5<\mathrm{pH}<8.5$ \\
\hline$\alpha_{2}(t)=\theta_{21}^{\alpha} p H(t-1)+\theta_{22}^{\alpha} \alpha(t-1)$ & $\mathrm{O}_{2}=1.0 \mathrm{mg} / \mathrm{L}$ \\
with $\theta_{21}^{\alpha}=0.04$ and $\theta_{22}^{\alpha}=0.35$ & $7.5<\mathrm{pH}<8.5$ \\
\hline$\beta_{1}(t)=\theta_{11}^{\beta} p H(t-1)+\theta_{12}^{\beta} \beta(t-1)$ & $\mathrm{O}_{2}=0.8 \mathrm{mg} / \mathrm{L}$ \\
with $\theta_{11}^{\beta}=0.05$ and $\theta_{12}^{\beta}=0.33$ & $7.5<\mathrm{pH}<8.5$ \\
\hline$\beta_{2}(t)=\theta_{21}^{\beta} p H(t-1)+\theta_{22}^{\beta} \beta(t-1)$ & $\mathrm{O}_{2}=1.0 \mathrm{mg} / \mathrm{L}$ \\
with $\theta_{21}^{\beta}=0.04$ and $\theta_{22}^{\beta}=0.31$ & $7.5<\mathrm{pH}<8.5$ \\
\hline
\end{tabular}

Table 1. First order models.

In the first operation zone $\left(\mathrm{O}_{2}=0.8 \mathrm{mg} / \mathrm{L}\right.$ and $7.5<\mathrm{pH}<$ $8.5)$, the steady state values of the efficiency rates were considered, it is to say in $\mathrm{pH}=7.5$ and $\mathrm{pH}=8.5$. With these values, the initial tuning of the models was made. The same procedure was executed for the remaining operation zone $\left(\mathrm{O}_{2}=1.0 \mathrm{mg} / \mathrm{L}\right.$ and $\left.7.5<\mathrm{pH}<8.5\right)$, where $\mathrm{pH}=7.5$ and $\mathrm{pH}=8.5$ were the steady state values of $\alpha$ and $\beta$ considered for tuning these models.

The mixing of these four models and fuzzy logic tools, compose the soft-sensor.

\section{The Fuzzy Multi-Model}

The equations wich describe the fuzzy multi-model behavior are:

$$
\begin{aligned}
& \alpha(t)=\alpha_{1}(t) k_{1}\left(O_{2}(t)\right)+\alpha_{2}(t) k_{2}\left(O_{2}(t)\right) \\
& \beta(t)=\beta_{1}(t) k_{1}\left(O_{2}(t)\right)+\beta_{2}(t) k_{2}\left(O_{2}(t)\right)
\end{aligned}
$$

Where $\alpha(t)$ and $\beta(t)$ are the outputs of the core models and $k_{i}$ are fuzzy membership functions, whose value goes between 0 and 1 depending on the $\mathrm{O}_{2}$ level presence in the process.

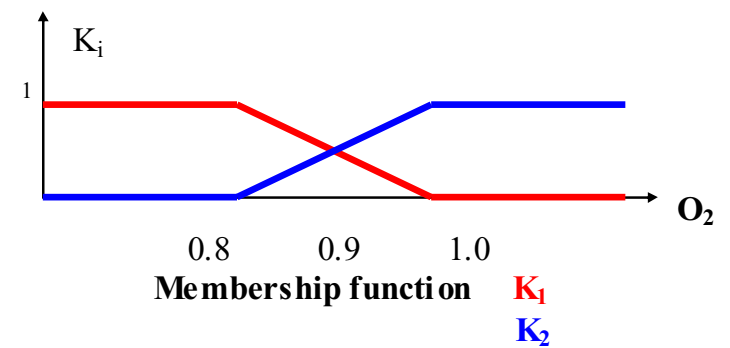

Figure 8. Fuzzy memberships depends on the level of dissolved oxygen, $\mathrm{O}_{2}$, in the reactor.

This system was developed for the operation conditions before mentioned. A change in some of these conditions would make necessary an updating procedure in the models parameters and in membership functions, reason why the operation range that allows estimate $\alpha$ and $\beta$ in real time is:

$$
7.5<\mathrm{pH}<8.5 \text { and } 0.8 \mathrm{mg} / \mathrm{L}<\mathrm{O}_{2}<1.0 \mathrm{mg} / \mathrm{L}
$$

An adaptation mechanism is proposed to update each one of the core models using the bias parameters $\delta_{i \alpha}$ and $\delta_{i \beta}$, as it shows ec. (4),

$$
\begin{aligned}
& \alpha_{i}(t)=\theta_{i 1}^{\alpha} p H(t-1)+\theta_{i 2}^{\alpha} \alpha(t-1)+\delta_{i \alpha} ; i=1,2 \\
& \beta_{i}(t)=\theta_{i 1}^{\beta} p H(t-1)+\theta_{i 2}^{\beta} \beta(t-1)+\delta_{i \beta} ; i=1,2
\end{aligned}
$$

where the adaptation mechanism is given by (5),

$$
\begin{array}{ll}
\delta_{i \alpha}(k)=\delta_{i \alpha}(k-1)+\eta_{\alpha}\left(\alpha(t)-\alpha_{i}(t)\right) ; & i=1,2 \\
\delta_{i \beta}(k)=\delta_{i \beta}(k-1)+\eta_{\beta}\left(\beta(t)-\beta_{i}(t)\right) ; & i=1,2
\end{array}
$$

and $\eta_{\alpha}$ and $\beta$ are empirical adaptation parameters.

Next graphic shows a comparison between real data of $\alpha$ (filtered) used to calculate the linear models in the first operation zone, and calculated data of $\alpha$ by the soft-sensor.

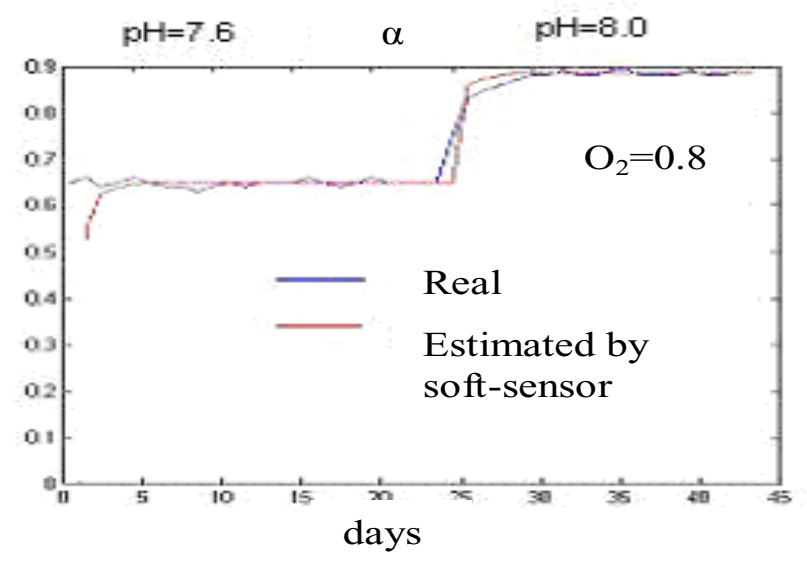

Figure 9. Fuzzy multi-model prediction and comparison with real values of $\alpha$ in the plant.

In figure 9 it can be seen a small error, and in addition that the initial $\alpha$ and $\beta$ values, calculated by the soft-sensor, depend on the system initial conditions.

The soft-sensor allows calculating all the $\alpha$ and $\beta$ values in steady state that may be reached to different $\mathrm{pH}$ and $\mathrm{O}_{2}$ set-point. Thus, by means of a numerical optimization, we can find the optimal set-point, to reach the maximum value of some objective function that represents the system efficiency.

\section{E. On-Line Optimization for $\alpha$ and $\beta$}

The most important function of the supervisory control system is the on-line optimization for an objective function that allows maintaining high $\alpha$ and $\beta$ values. In order to obtain this an exhaustive optimization method is used, 
which consists in evaluating an objective function (equation 6) within an operation interval for $\mathrm{pH}$ and $\mathrm{O}_{2}$, with a fixed step increase for both cases. This allows getting a fine mesh that contains all the values in steady state for this objective function, in the different $\mathrm{pH}$ and $\mathrm{O}_{2}$, set-points. After, this mesh is sorted in terms of the optimization variable, so that the maximum value of the objective function that fulfills the specified restrictions is reached, being therefore the arguments $\left(\mathrm{pH}\right.$ and $\left.\mathrm{O}_{2}\right)$ that corresponds to the optimal value. Although this method requires an intensive processor use, has the advantage to assure that the result that finds corresponds to the global optimum.

$$
\begin{aligned}
& \operatorname{Max}\{Z=\alpha+\beta\} \\
& \text { s.t. } \\
& 7.5 \leq p H \leq 8.5 \\
& 0.8 \leq O_{2} \leq 1.0 \\
& 0.9 \leq \alpha \leq 1.0 \\
& 0.8 \leq \beta \leq 1.0
\end{aligned}
$$
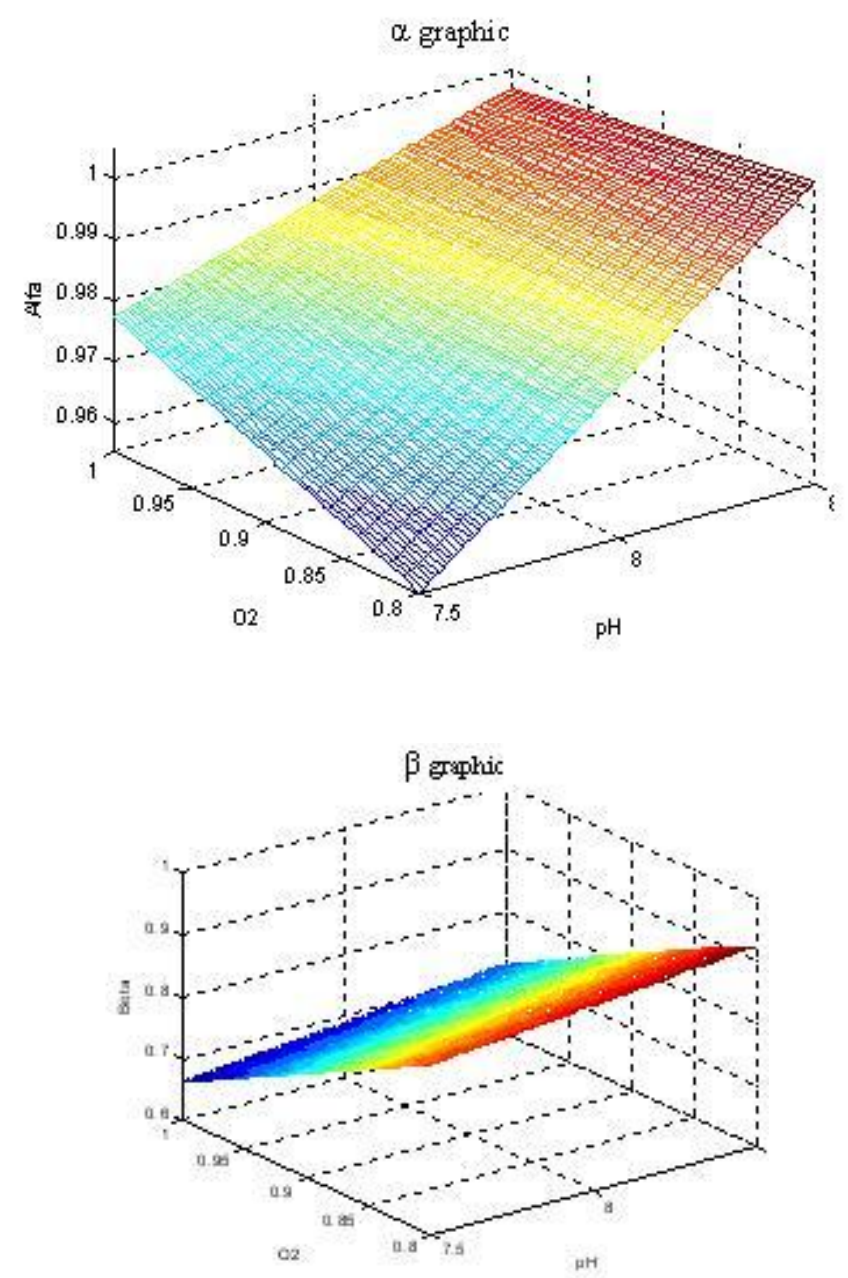

Figure 10. $\alpha$ and $\beta$ static mesh.

In order to obtain the calculation demand, is necessary to consider that since the optimization variables are restricted, only 20,000 evaluations of the objective function are required to achieve a grid of $0.001 \mathrm{mg} / \mathrm{L}$ in $\mathrm{O}_{2}$ and 0.01 in $\mathrm{pH}$. All the required computations were made in time intervals lesser than 1 minute running on a Pentium IV PC to $2.4 \mathrm{GHz}$. This optimization is only made when the softsensor models are updated, that is once to the day at the most.

This routine works using the soft-sensor outputs, which are $\alpha$ and $\beta$ values that can be reached in the constrained operation interval, allowing crossing the meshes that are seen in figure 10 . Once the routine finds the maximum of this function, it goes to that point with a speed established by the operator.

\section{The Supervisory CONTROL SySTEM}

The supervisory control system mix soft-sensor and online optimization, with the purpose of maintaining a high efficiency in the reactor (see figure 11). For this purpose, the soft-sensor reads the present values of $\mathrm{pH}$ and $\mathrm{O}_{2}$ and does $\alpha$ and $\beta$ estimation. Then, the on-line optimization is executed to find new values for $\mathrm{pH}$ and $\mathrm{O}_{2}$ so that the objective function is optimal. These values are used as references for the regulatory control.

This system was programmed in Matlab 6.5 and the communication with the programmable logic controller (PLC), is made using DDE protocol.

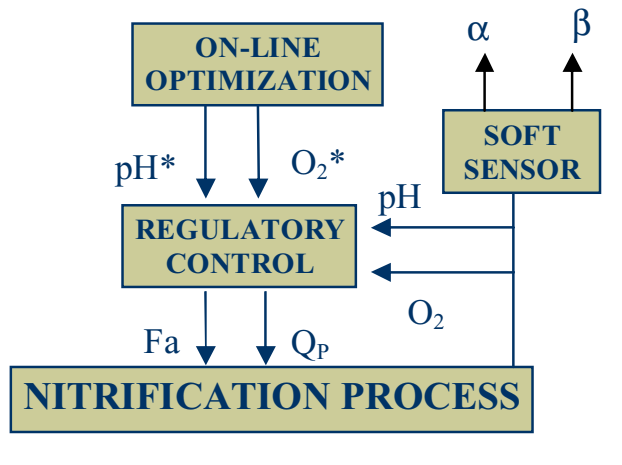

Figure 11. Flow Sheet of supervisory control system.

The graphical user interface was developed using the Guide Matlab Toolbox, and it is shown in figure 12. This system has two operation modes: Automatico $I$ and Automatico II. In the left superior corner there is the softsensor and in the central inferior part, are located plots for $\alpha$ and $\beta$ trends, with a time period of one day. In addition it has options for models update and gives steady state estimations for $\alpha$ and $\beta$ in the case that the $\mathrm{pH}$ and $\mathrm{O}_{2}$ values given by the on-line optimizer are applied to the process.

Automatico I mode, allows the user to set a sequence of 6 different set-points, that they will be repeated cyclically according to specified time intervals. This with the purpose for operating in various set- points automatically.

Automatico II mode, executes an optimization routine for to get the maximum value of an objective function with the present models, allowing maintaining high $\alpha$ and $\beta$ values. 
Actually, the supervisory system is in evaluation stage. On the next figure (fig.13), there is a graph showing data collected in the first operation week with the supervisory system, where experimental data obtained from chemical analyses is compared with the estimated data obtained by the soft-sensor.

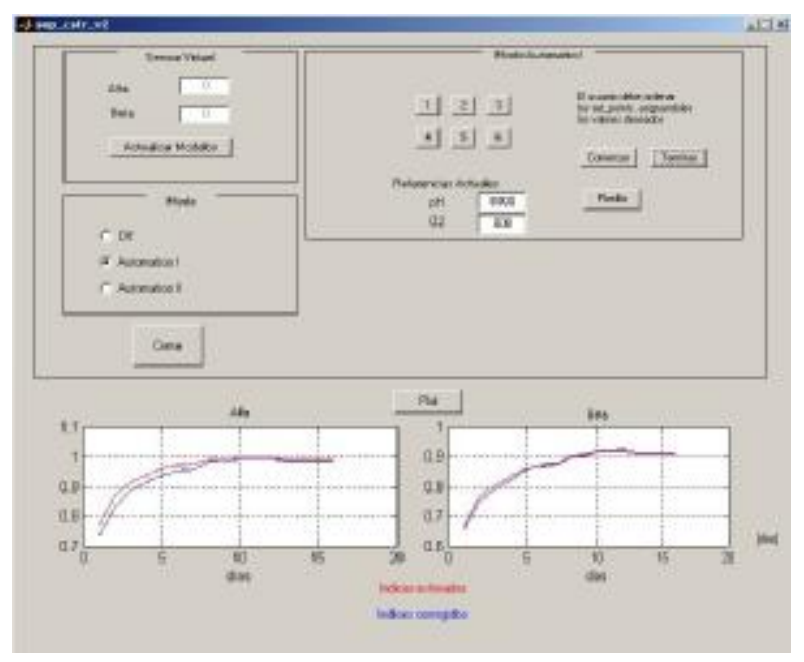

Figure 12. Supervisor control graphical interface.

It can be seen that both trends fit very good, presenting a standard deviation of $7,56 \%$ and although the dynamic behavior have viewable errors, the estimations that the softsensor does for steady state are acceptable, and they approach enough the experimental values obtained from the laboratory analysis.

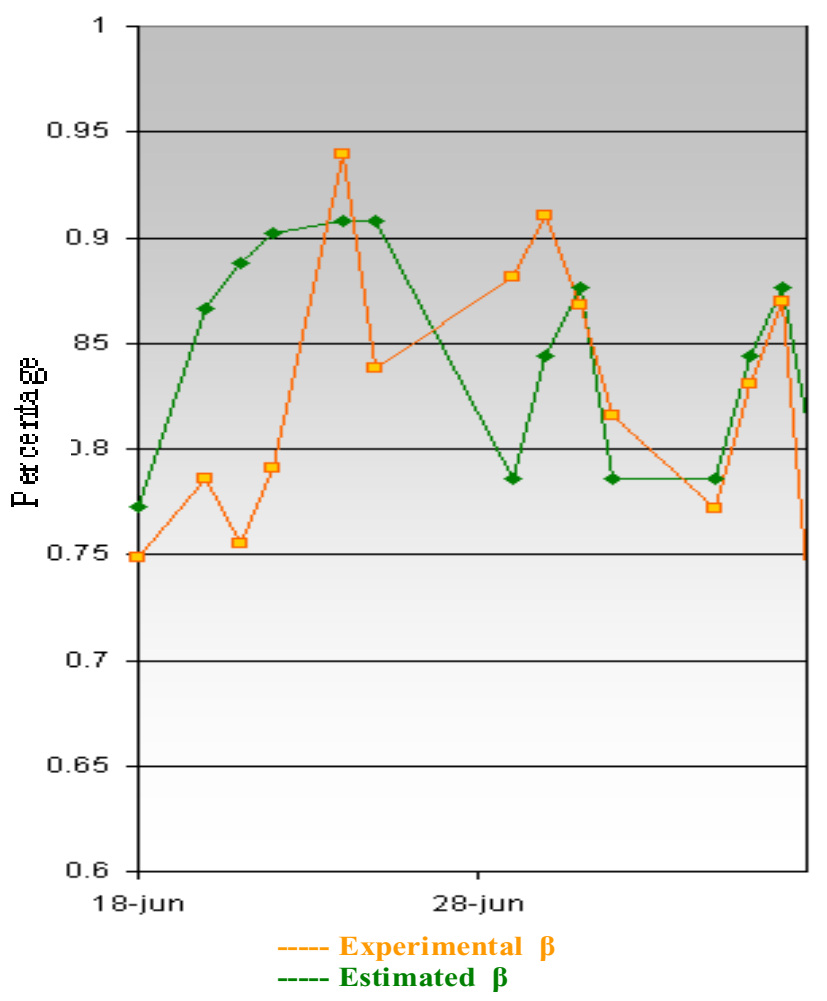

Figure 13. Real $\beta \mathrm{v} / \mathrm{s}$ Estimated $\beta$.

\section{Conclusions ANd Future Research}

This work is an advance in the development of supervision systems that allow maintaining simultaneously in a high value, the nitrite accumulation and ammonia degradation in an activated sludge process. Although this work is based on the use of simplified models, this is a simple and innovating solution in this kind of systems. In this paper it was decided on the use of linear fuzzy multimodels of first order. Nevertheless, the model does not explain the external disturbances impact like changes in the feeding concentration or temperature, those that are considered only when the model is adapted, when new laboratory measurements are entering. Would be advisable to explore what happens if phenomenological models are used to get a greater explanation level from the soft-sensor to external changes and with this to react to disturbances.

\section{ACKNOWLEDGEMENTS}

The authors are grateful for financial support provided by FONDECYT project 1030317.

\section{REFERENCES}

[1] M.Tomiello, E.Perrin, M.Roubens., M.Crine (1999). "Fuzzy Control Of An Activated Sludge process" . Proceedings of the $2^{\text {nd }}$ Congress of Chemical Engineering (ECCE2), Montpellier, France, October 5-7.

[2] Antileo, C., Roeckel, M., Wiesman, U. (2003). "High Nitrite Buildup During Nitrification in a Rotating Disk Reactor". Water Environment Research. $\left(\mathrm{N}^{0} 0112177\right)$, in press.

[3] Araneda, J (2003). "Diseño y Simulación de un Sistema de Control de un reactor Biológico de Flujo Continuo CSTR". (in spanish) Engineering Thesis, Universidad de la Frontera.

[4] Huenupán,F (2004). "Implementación de Estrategias de Control para Reactores Biológicos Nitrificantes". (in spanish) Engineering Thesis, Universidad de la Frontera.

[5] E. Ali (2001). " $\mathrm{pH}$ control using PI control algorithms with automatic tuning method". Institution of Chemical Engineers, Trans Ichem E, Vol 79, part A, $611-620$.

[6] Sandra J. Norquay, Ahmet Palazoglu, and Jose Alberto Romagnoli (1999). "Application of Wiener model predictive control (WMPC) to a PH neutralization Experiment". IEEE Transactions on Control System Technology, vol 7, $\mathrm{N}^{\circ} 4,437-445$.

[7] Turk O, Mavinik D S (1898). "Maintaining Nitrite Buildup in a System Acclimated to Free Ammonia". Water Research, Vol 11, No 23, pp. 13831338 . 